Resumo

\title{
O efeito do treinamento de circuito utilitário militar sobre a regulação autonômica cardíaca em militares do Exército brasileiro
}

Julio Cesar de Carvalho Moura Junior Bsci, Jairo José Monteiro Morgando MSci

Introdução: A Pista de Treinamento de circuito utilitário militar é uma das formas de treinamento físico previstas no manual de Campanha de Treinamento Físico do Exército, o C 20-20 (2002), sendo orientada para o desenvolvimento neuromuscular e cardiopulmonar. Essa pista possui uma sequência de exercícios intercalados em estações, sem intervalos de recuperação entre as estações. A intensidade elevada pode levar a regulação autonômica cardíaca a níveis não desejados. Portanto, é necessário verificar os marcadores de variabilidade de frequência cardíaca, mesmo que agudamente.

Objetivo: Verificar os efeitos da pista de treinamento de circuito utilitário militar, sobre a regulação autonômica.

Métodos: Foram realizadas três passagens na pista, com intensidades de 30, 45 e 60 segundos para execução de cada exercício, onde os oito participantes (alunos da EsEFEx 2015), utilizaram um frequencímetro cardíaco, para aferir os marcadores da variabilidade da frequência cardíaca durante as passagens na pista.

Resultados: Após realizar os testes de ANOVA e Kruskal Wallis, verificamos que dos seis marcadores selecionados para estudo, somente o RMSSD, mostrou diferença significante estatística e somente entre duas das três passagens realizadas na pista.

Conclusão: Foi encontrada diferença estatisticamente significativa em apenas um dos indicadores cardíacos, na execução da pista no tempo de 30 para 60 segundos. 